\title{
Avaliação de uma bacterina autógena contra meningite estreptocócica em suínos
}

\author{
Evaluation of an Autogenous Bacterin Against Streptococcal Meningitis in Swine \\ Carlos José Locatelli Salgadoํㅣ , José Lúcio dos Santos² \& Walter Vieira Guimarães ${ }^{3}$ \\ RESUMO
}

A meningite estreptocócica suína, causada pelo Streptococcus suis, é uma doença emergente na suinocultura industrializada. Apesar da mortalidade raramente ultrapassar 5\%, as perdas econômicas são estimadas em centenas de milhões de dólares por ano e a vacinação não tem mostrado resultados satisfatórios. Este trabalho foi desenvolvido com o objetivo de determinar a eficácia de uma bacterina autógena contra $S$. suis sorotipo 2 e testar vias e doses de inoculação. Foram realizados dois experimentos em épocas diferentes com 64 animais em cada experimento. No Experimento I, 32 animais foram vacinados e 32 animais receberam placebo, sendo ambos os grupos desafiados aos 60 dias. No experimento II, os animais foram divididos em quatro grupos: NVIP - 16 animais não vacinados e desafiados pela via intraperitoneal; VIP - 16 animais vacinados e desafiados pela via intraperitoneal; NVIV - 16 animais não vacinados e desafiados pela via intravenosa; e VIV - 16 animais vacinados e desafiados pela via intravenosa. Todos os grupos foram desafiados aos 88 dias de idade. No Experimento I, não foi possível detectar diferença significativa na proteção, sinais clínicos e lesões $(\mathrm{P}>0.05)$ entre os grupos não vacinado e vacinado. Entretanto, o isolamento do $S$. suis e a média da contagem bacteriana foi maior $(\mathrm{P}<0.01)$ no grupo não vacinado. Os resultados observados no Experimento II nos grupos NVIV e VIV apresentaram proteção, sinais clínicos e lesões similares $(\mathrm{P}>0.05)$. Os grupos NVIP e VIP apresentaram diferenças significativas para proteção, sinais clínicos, lesões, número de isolamentos positivos e média da contagem bacteriana do agente $(\mathrm{P}<0.01)$. Portanto, a via de desafio intravenosa não se mostrou adequada para esse tipo de experimento e a via intraperitoneal apresentou aspectos favoráveis. A vacina protegeu os animais contra a infecção pelo Streptococcus suis sorotipo 2 de alta virulência, com uma eficácia estimada de $87,5 \%$ nas condições experimentais.

Descritores: bacterina autógena, vacina, Streptococcus suis, proteção, desafio.

\begin{abstract}
The streptococcal meningitis in swine, caused by Streptococcus suis, is an emergent disease in the industrialized swine production. In spite of the mortality rarely surpass 5\%, the economical losses are estimated in hundreds of million of dollars per year and the vaccination has not showed satisfactory results. This work was developed with the objective to determine the efficiency of an autogenous bacterin against Streptococcus suis sorotipo 2 and to test route and inoculation doses. Two experiments were accomplished in different times with 64 animals in each experiment. In the Experiment I, 32 animals were vaccinated and 32 animals received placebo, being both groups challenged at the 60 days of age. In the Experiment II, the animals were divided in four groups: NVIP - 16 animals not vaccinated and challenged by the route intraperitoneal; VIP - 16 vaccinated animals and challenged by the route intraperitoneal; NVIV - 16 animals not vaccinated and challenged by the intravenous route; and VIV - 16 vaccinated animals and challenged by the intravenous route. All groups were challenged at the 88 days of age. In the Experiment I, it was not possible to detect significant difference in the protection, clinical signs and lesions $(\mathrm{P}>0.05)$ among the groups not vaccinated and vaccinated. However, the isolation of $S$. suis and the average of the bacterial count was higher $(\mathrm{P}<0.01)$ in the group not vaccinated. The results observed in the Experiment II in the groups NVIV and VIV were similar for protection, clinical signs and lesions (P>0.05). The groups NVIP and VIP presented significant differences for protection, clinical signs, lesions, number of positive isolations and average of the bacterial agent count $(\mathrm{P}<0.01)$. The intravenous challenge route was not shown appropriate for that experiment type and the route intraperitoneal presented favorable aspects. The vaccine protected the animals against the infection for Streptococcus suis serotype 2 of high virulence, with a efficacy around $87.5 \%$ in the experimental conditions.
\end{abstract}

Key words: autogenous bacterin, vaccine, Streptococcus suis, protection, challenge.

Received: J une 2003

Accepted: November 2003

\footnotetext{
${ }^{1}$ Mestrando da Universidade Federal de Viçosa (UFV). ${ }^{2}$ Setor de Medicina Preventiva, Departamento de Veterinária - UFV - MG, Brasil. ${ }^{3}$ Microvet Microbiologia Veterinária Especial Ltda., Viçosa. CORRESPONDÊNCIA: J. L. Santos [jlucio@ufv.br]
} 


\section{INTRODUÇÃO}

A meningite estreptocócica dos suínos é uma doença emergente na suinocultura industrializada, causada pelo Streptococcus suis, produzindo quadros de septicemia, artrite e meningite nos animais [8]. As perdas econômicas devido ao $S$. suis são expressivas, sendo estimadas em centenas de milhões de dólares por ano, apesar da mortalidade raramente ultrapassar 5\% [11]. Medidas convencionais de controle, como a vacinação não tem mostrado resultados satisfatórios [6]. Até o momento, o método mais efetivo de limitar as perdas econômicas é o tratamento de animais doentes com antibióticos na ração ou água. Em rebanhos grandes o controle da meningite pode ser difícil e muito caro [3]. Além disso, os antibióticos estão se tornando menos efetivos devido ao aumento da resistência dos isolados de $S$. suis [1,9] e seu uso é questionado devido aos resíduos dos antimicrobianos na carcaça. Muitas dificuldades existem para que a vacinação seja efetiva. Uma delas é que muitos rebanhos de suínos são infectados com múltiplos sorotipos de $S$. suis e as bacterinas não produzem imunidade cruzada entre a maioria dos sorotipos [11]. Neste caso o uso de vacinas inativadas autógenas pode apresentar resultados promissores [10].

Este trabalho foi desenvolvido com os objetivos de avaliar a eficiência de uma bacterina autógena na proteção de leitões vacinados e desafiados com o S. suis sorotipo 2 de alta virulência e testar vias e doses de desafio adequados a esse tipo de experimento.

\section{MATERIAIS E MÉTODOS}

Os experimentos foram realizados no Departamento de Veterinária (DVT) da Universidade Federal de Viçosa (UFV). Os animais foram adquiridos de um único rebanho classificado como GRSC (Granja de Suínos Certificada), de alto status sanitário e livre do Streptococcus suis sorotipo 2. No experimento I os animais foram divididos em dois grupos, sendo 32 animais do grupo controle não vacinado (NV) e 32 animais do grupo vacinado (V). No Experimento II os animais foram distribuídos em quatro grupos experimentais: 1) 16 animais não vacinados e desafiados pela via intraperitoneal (Grupo NVIP); 2) 16 animais vacinados e desafiados pela via intraperitoneal (Grupo VIP); 3) 16 animais não vacinados e desafiados pela via intravenosa (Grupo NVIV); e 4) 16 animais vacinados e desafiados pela via intravenosa (Grupo VIV).

A amostra liofilizada de $S$. suis sorotipo 2 (MVLG-789), cedida pelo laboratório Microvet ${ }^{\mathrm{a} 1}$, foi utilizada para produção da bacterina e posteriormente para desafio dos animais. A amostra foi isolada das meninges de um suíno que apresentava quadro clínico de meningite pelo $S$. suis sorotipo 2. A amostra liofilizada do $S$. suis foi rehidratada e inoculada em Agar Todd Hewitt ${ }^{2}$ acrescido de $10 \%$ de sangue desfibrinado de carneiro e incubada a $37^{\circ} \mathrm{C}$ "over night". A massa bacteriana foi coletada em salina tamponada (PBS pH $7,2)$ e padronizada para a concentração aproximada de $3 \times 10^{9} \mathrm{UFC} / \mathrm{mL}$, por densidade óptica da suspensão. A curva padrão foi determinada anteriormente, fazendose leituras de densidade óptica e contagens de colônias em placas. Após a padronização, foi preparado e analisado um esfregaço corado pela Coloração de Gram, com o intuito de verificar contaminação da suspensão por outros microorganismos. A suspensão da cultura foi inativada pela adição de formol para concentração final de $0,2 \%$ e mantido por $12 \mathrm{~h}$. Após a inativação uma alíquota da cultura foi semeada em ágar sangue base $^{2}$ acrescido de $10 \%$ de sangue desfibrinado de carneiro e em caldo tioglicolato ${ }^{2}$ ambos incubadas a $37^{\circ} \mathrm{C}$ por $48 \mathrm{~h} \mathrm{e} 72 \mathrm{~h}$, respectivamente. A bacterina consistiu na suspensão bacteriana inativada com adição de $20 \%$ de adjuvante oleoso (emulsão água em óleo). Na suspensão de $S$. suis usada para o desafio, utilizou-se a mesma amostra e os procedimentos de cultura, concentração e teste de pureza descritos.

Os animais receberam a primeira dose $(2,0 \mathrm{~mL})$ da vacina aos 25 dias de idade e a segunda $(3,0 \mathrm{~mL})$ aos 45 dias de idade no experimento I e aos 50 dias no experimento II, por via intramuscular profunda, no pescoço. Os animais não vacinados receberam, na mesma data, a aplicação do placebo (salina tamponada mais $20 \%$ do adjuvante oleoso). No experimento I o desafio foi feito aos 60 dias de idade, com uma dosagem de 4,3 $\mathrm{x} 10^{9} \mathrm{UFC} / \mathrm{mL}$, sendo inoculados $2 \mathrm{~mL}$ em cada animal e no experimento II foi feito aos 88 dias de idade, sendo utilizada uma dosagem de 2,4 x $10^{9} \mathrm{UFC} / \mathrm{mL}$ e inoculados $3 \mathrm{~mL}$ em cada animal. Durante 7 dias pós-inoculação foi realizada avaliação diária, dos sinais clínicos (depressão, artrite, sinais nervosos, sinais respiratórios e temperatura retal). Os animais que não morreram até o sétimo dia foram sacrificados e submetidos à necropsia. Os animais foram necropsiados assim que detectada 
sua morte, sendo avaliados quanto aos seguintes parâmetros: peritonite, pleurisia/pericardite, meningite e artrite. Durante os procedimentos de necropsia foram coletados assepticamente swabs do cérebro, sangue cardíaco, articulações, peritônio e pleura. Esses swabs foram repassados em Agar sangue de carneiro a $5 \%$ e incubados a $37^{\circ} \mathrm{C}$ por 24 horas. No mínimo três colônias que cresceram na placa foram submetidos a coloração de gram, testes bioquímicos e sorotipagem. Os resultados foram submetidos a uma análise qualitativa pelo teste de Qui-quadrado $\left(\chi^{2}\right)$ e as médias da temperatura retal e contagem bacteriana submetidas à ANOVA e teste de comparação de médias (Teste $\mathrm{t}$ de Student). A taxa de proteção da vacina foi calculada utilizando o programa Epiinfo 6.4 $4^{3}$ Um valor de $\mathrm{p} \leq 0.05$ (95\% de probabilidade), foi considerado significante.

\section{RESULTADOS}

A maior parte dos animais no experimento I (61/64) apresentaram sinais clínicos graves da doença, com apatia e artrite de moderada a severa. A média da temperatura retal observada no grupo não vacinado foi de $40,33 \pm 0,18^{\circ} \mathrm{C}$ e nos vacinados de 40,01 \pm $0,17^{\circ} \mathrm{C}$ (Figura 1). As médias não diferiram significativamente entre si $(\mathrm{P}>0.05)$. Em 14/32 animais do grupo não vacinado e 11/32 do grupo vacinado apresentaram sinais nervosos clássicos da doença, com pedalagem, opstotomo, nistagmo e esclera hiperemica. Todos os animais do experimento I que morreram apresentaram previamente sinais nervosos claros, exceto dois animais do grupo vacinado que morreram com menos de 24 horas pós desafio. Em 8/32 animais não vacinados e 5/32 dos vacinados apresentaram sinais respiratórios, sendo observado tosse, dispnéia e secreção nasal serosa e mucopurulenta. Não houve diferença significativa $(\mathrm{P}>0.05)$ no número de animais com sinais clínicos entre o grupo vacinado e não vacinado, para qualquer parâmetro observado. Os sinais clínicos observados foram semelhantes nos dois grupos (Tabela 1).

No experimento II o número de animais que apresentaram sinais clínicos foi maior no grupo NVIP $(\mathrm{P}<0.01)$ do que no VIP (Tabela 1). Os grupos VIV e NVIV, ambos desafiados pela via intravenosa, apresentaram sinais clínicos semelhante, não sendo possível verificar diferenças significativa entre eles $(\mathrm{P}>0.2)$. Os animais dos grupos desafiados pela via intraperitoneal apresentaram uma temperatura retal média de $40,15 \pm 0,21^{\circ} \mathrm{C}$ (não vacinados) e $39,65 \pm$ $0,12^{\circ} \mathrm{C}$ (vacinados), sendo $0,5^{\circ} \mathrm{C}$ mais elevada $(\mathrm{P}=0.01)$ no grupo não vacinado (Figura 2$)$. A temperatura retal média dos grupos desafiados pela via intravenosa foi de $39,91 \pm 0,16^{\circ} \mathrm{C}$ (não vacinados) e de $39,89 \pm 0,16^{\circ} \mathrm{C}$ (vacinados), não diferindo significativamente entre si $(\mathrm{P}=0.39)$.

Não foi encontrada diferença significativa entre o número de animais apresentando lesões nos grupos do experimento I $(\mathrm{P}>0.05)$. Oito animais do grupo $\mathrm{NV}$ e dois do grupo $\mathrm{V}$ apresentaram lesões graves de encefalite, com depósitos de material purulento nas meninges. As lesões pulmonares observadas foram áreas de consolidação (hepatização), e a porcentagem média de área pulmonar atingida no grupo $\mathrm{NV}$ foi de $15,26 \%$ e no grupo V de $8,88 \%$.

O número de animais com lesões sugestivas de infecção pelo $S$. suis não diferiu estatisticamente entre os grupos vacinado e não vacinado com desafio intravenoso $(\mathrm{P}>0.2)$. Entretanto, foi observada diferença significativa $(\mathrm{P}<0.05)$ no número de animais com lesões entre o grupo VIP e os demais grupos do experimento II.

A Tabela 2 apresenta o resultado do número de animais com isolamento do $S$. suis. No experimento I, no grupo $\mathrm{V}$, o isolamento ocorreu em 17/32 animais $(53,1 \%)$ e no grupo NV em 30/32 animais $(93,75 \%)$, sendo encontrada diferença significativa $(\mathrm{P}<0.01)$ entre os dois grupos. Entretanto, quando comparados o isolamento bacteriano nos diversos órgãos, só foi observada diferença significativa para o isolamento na articulação $(\mathrm{P}<0.01)$ e no sangue cardíaco $(\mathrm{P}<0.05)$. No peritônio, pleura e cérebro, apesar da diferença numérica, não foi detectada diferença significativa $(\mathrm{P}>0.2)$. A média da contagem bacteriana (UFC/mL) foi significativamente $(\mathrm{P}<0.01)$ mais elevada no grupo $\mathrm{NV}(209,92 \pm 54,99)$ do que no grupo $\mathrm{V}(102,34 \pm 40,99)$. A média da contagem bacteriana nos nove animais do grupo não vacinado mortos durante o experimento I foi de 435,23 $\pm 134,41 \mathrm{UFC} / \mathrm{mL}$ e dos 10 animais vacinados foi de 219,32 $\pm 108,13$ $\mathrm{UFC} / \mathrm{mL}$, sendo mais elevada no grupo não vacinado $(\mathrm{P}=0.02)$. Em todos os animais que morreram durante o experimento, obteve-se o isolamento do $S$. suis, com exceção de dois animais do grupo $\mathrm{V}$ que morreram com menos de 24 horas após inoculação.

No experimento II, nos grupos desafiados pela via intravenosa, foi isolado do $S$. suis em 9/16 animais 
do grupo não vacinado e em 3/16 do grupo vacinado, sendo observada diferença significativa entre eles $(\mathrm{P}<0.05)$. A contagem bacteriana média para o grupo NVIV foi de $140,13 \pm 71,8 \mathrm{UFC} / \mathrm{mL}$ e no grupo VIV de $18 \pm 39,2 \mathrm{UFC} / \mathrm{mL}$, sendo estatisticamente diferentes entre si $(\mathrm{P}<0.01)$. Nos grupos desafiados pela via intraperitoneal, foi isolado o $S$. suis de 9/16 animais do grupo NVIP e de nenhum animal do grupo VIP. Houve diferença significativa em relação ao número de isolamentos positivos entre os grupos VIP e NVIP $(\mathrm{P}<0.01)$ em todos os locais onde se tentou o isolamento. A contagem bacteriana média do grupo de animais não vacinados foi de 295,25 $\pm 134,68 \mathrm{UFC} / \mathrm{mL}$, enquanto que no grupo vacinado não houve isolamento bacteriano $(\mathrm{P}<0.01)$. Em todos os cinco animais mortos foi possível realizar o isolamento do $S$. suis em pelo menos três locais diferentes, sendo que a média da contagem bacteriana nesses animais foi de 696,8 $\pm 347,31 \mathrm{UFC} / \mathrm{mL}$.

No experimento I, os animais foram desafiados 20 dias após a segunda dose da vacina, aos 60 dias de idade. Não houve diferença significativa $(\mathrm{P}>0.05)$ no número de doentes, sobreviventes sadios e de mortes nos dois grupos (Tabela 3). No experimento II, os animais foram desafiados 40 dias após terem recebido a segunda dose da vacina. Não houve diferença significativa no número de mortes, sobrevi- ventes sadios e sobreviventes doentes nos Grupos NVIV e VIV ( $\mathrm{P}>0.05$ ), o que confirma o resultado apresentado pelo experimento I. Entretanto, os animais do grupo vacinado e não vacinado desafiados pela via intraperitoneal, apresentaram diferença significativa $(\mathrm{P}<0.01)$ entre si em relação ao número de animais doentes e sadios. Também, o número de mortes foi significativamente maior $(\mathrm{P}<0.01)$ no grupo não vacinado em relação ao grupo vacinado (Tabela 3). No experimento II, a taxa de proteção da vacina nos animais desafiados pela via intraperitoneal, foi de $87,5 \%$, quando comparado o número de animais sadios e doentes. No entanto, a taxa de proteção da mesma vacina nos animais desafiados pela via intravenosa foi $0 \%$.

\section{DISCUSSÃO}

Observando os resultados do experimento I, pode-se concluir que a proteção da vacina nas condições experimentais não foi adequada. Um dos principais fatores que pode afetar a proteção da vacina em condições experimentais é a forma de desafio utiliza$\mathrm{da}$, quase sempre intravenosa, o que não representa a forma natural de desafio da doença [3,4,13]. Por isso, decidiu-se realizar o Experimento II, no qual foi testada também a via de desafio intraperitoneal. Torremorell \& Pijoan [12] testaram a via intraperitoneal e conse-

Tabela 1. Número de animais com sinais clínicos - Experimentos I e II.

\begin{tabular}{ccccccc}
\hline Experimentos & Grupos & Apatia & Artrite & Febre $(>40,5)$ & Sinais nervosos & Sinais respiratórios \\
\hline \multirow{2}{*}{ I } & NV & $31 / 32^{\mathrm{A}}$ & $31 / 32^{\mathrm{A}}$ & $17 / 32^{\mathrm{A}}$ & $14 / 32^{\mathrm{A}}$ & $8 / 32^{\mathrm{A}}$ \\
& $\mathrm{V}$ & $29 / 32^{\mathrm{A}}$ & $29 / 32^{\mathrm{A}}$ & $19 / 32^{\mathrm{A}}$ & $11 / 32^{\mathrm{A}}$ & $5 / 32^{\mathrm{A}}$ \\
\hline & $\mathrm{NVIP}$ & $16 / 16^{\mathrm{A}}$ & $16 / 16^{\mathrm{A}}$ & $12 / 16^{\mathrm{A}}$ & $0 / 16^{\mathrm{B}}$ & $0 / 16^{\mathrm{B}}$ \\
II & VIP & $2 / 16^{\mathrm{B}}$ & $3 / 16^{\mathrm{B}}$ & $3 / 16^{\mathrm{B}}$ & $0 / 16^{\mathrm{B}}$ & $0 / 16^{\mathrm{B}}$ \\
& NVIV & $16 / 16^{\mathrm{A}}$ & $16 / 16^{\mathrm{A}}$ & $11 / 16^{\mathrm{A}}$ & $0 / 16^{\mathrm{B}}$ & $0 / 16^{\mathrm{B}}$ \\
& VIV & $15 / 16^{\mathrm{A}}$ & $14 / 16^{\mathrm{A}}$ & $4 / 16^{\mathrm{B}}$ & $0 / 16^{\mathrm{B}}$ & $0 / 16^{\mathrm{B}}$ \\
\hline AB Letras diferentes na mesma coluna representa que foi encontrada diferença estatística significativa $(\mathrm{P}<0.05)$ entre os grupos experimentais.
\end{tabular}

Tabela 2. Número de animais com isolamento positivo do Streptococcus suis, nos diversos locais onde se tentou o isolamento - Experimentos I e II.

\begin{tabular}{|c|c|c|c|c|c|c|}
\hline Experimentos & Grupos & Articulação & Peritônio & Pleura & Cérebro & Sangue cardíaco \\
\hline \multirow{2}{*}{ I } & NV & $20 / 32^{A}$ & $12 / 32^{A}$ & $11 / 32^{A}$ & $9 / 32^{A}$ & $14 / 32^{A}$ \\
\hline & V & $7 / 32^{\mathrm{B}}$ & $7 / 32^{A}$ & $8 / 32^{A}$ & $5 / 32^{A}$ & $7 / 32^{\mathrm{B}}$ \\
\hline \multirow{4}{*}{$\|$} & NVIP & $7 / 16^{A}$ & $8 / 16^{A}$ & $5 / 16^{A}$ & $7 / 16^{A}$ & $7 / 16^{A}$ \\
\hline & VIP & $0 / 16^{\mathrm{B}}$ & $0 / 16^{\mathrm{B}}$ & $0 / 16^{B}$ & $0 / 16^{\mathrm{B}}$ & $0 / 16^{\mathrm{B}}$ \\
\hline & NVIV & $7 / 16^{A}$ & $5 / 16^{A}$ & $4 / 16^{A}$ & $4 / 16^{A}$ & $6 / 16^{A}$ \\
\hline & VIV & $2 / 16^{B}$ & $0 / 16^{B}$ & $0 / 16^{B}$ & $1 / 16^{A}$ & $0 / 16^{B}$ \\
\hline
\end{tabular}


Tabela 3. Animais sobreviventes sadios, sobreviventes doentes e mortos - Experimentos I e II.

\begin{tabular}{ccccc}
\hline Experimentos & Grupos & Sobreviventes sadios & Sobreviventes doentes & Mortos \\
\hline I & NV & $1 / 32(3 \%)^{\mathrm{A}}$ & $22 / 32(69 \%)^{\mathrm{A}}$ & $9 / 32(28 \%)^{\mathrm{A}}$ \\
& V & $3 / 32(9 \%)^{\mathrm{A}}$ & $19 / 32(60 \%)^{\mathrm{A}}$ & $10 / 32(31 \%)^{\mathrm{A}}$ \\
\hline & NVIP & $0 / 32(0 \%)^{\mathrm{A}}$ & $11 / 16(69 \%)^{\mathrm{A}}$ & $5 / 16(31 \%)^{\mathrm{A}}$ \\
& VIP & $14 / 16(87 \%)^{\mathrm{B}}$ & $2 / 16(12 \%)^{\mathrm{B}}$ & $0 / 16(0 \%)^{\mathrm{B}}$ \\
& NVIV & $1 / 16(6 \%)^{\mathrm{A}}$ & $15 / 16(94 \%)^{\mathrm{A}}$ & $0 / 16(0 \%)^{\mathrm{B}}$ \\
& VIV & $1 / 16(6 \%)^{\mathrm{A}}$ & $14 / 16(88 \%)^{\mathrm{A}}$ & $1 / 16(6 \%)^{\mathrm{B}}$ \\
\hline${ }^{A B}$ Letras diferentes na mesma coluna representa que foi encontrada diferença estatística significativa $(\mathrm{P}<0.05)$ entre os grupos experimentais.
\end{tabular}

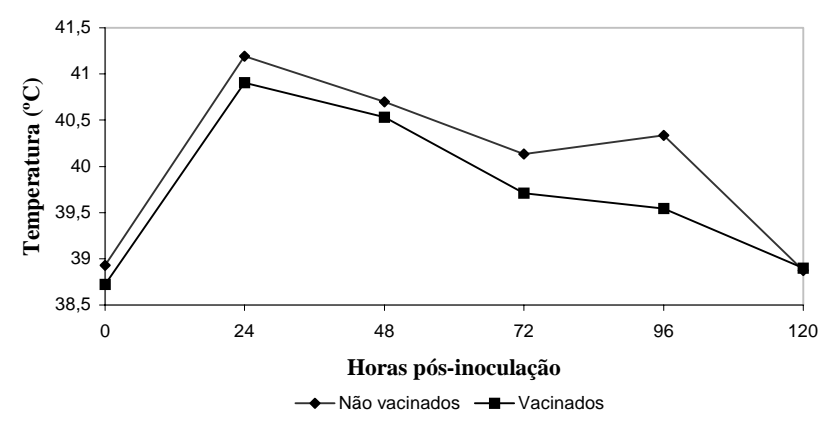

Figura 1. Média da temperatura retal nos grupos de animais do Experimento I.

guiram reproduzir a doença em quase todos os animais. A escolha da via intraperitoneal foi feita porque existem poucos estudos sobre esta via como método alternativo de desafio para esse tipo de experimento. No experimento II, os grupos desfiados pela via intraperitoneal apresentaram resultados que mostram eficiência da vacina na proteção dos animais. Os animais do grupo VIP não apresentaram quadros clínicos graves da doença. Já no grupo NVIP, todos os animais apresentaram quadros graves da doença. Quando desafiados pela via intravenosa, os animais vacinados apresentaram quadros clínicos semelhantes aos não vacinados, o que também pôde ser observado no experimento I.

Analisando-se os resultados apresentados nos experimentos I e II, é possível verificar uma interação entre o efeito da vacina e a via de desafio utilizada, pois somente o grupo de animais vacinados e desafiados pela via intraperitoneal apresentaram diferença estatística significativa $(\mathrm{P}<0.01)$ em relação à proteção, sinais clínicos, lesões e isolamento do agente entre os diversos grupos experimentais. No experimento II, os resultados de proteção da vacina foram influenciados pela via de desafio. Quando foi utilizada a via de desafio intraperitoneal a proteção da vacina $(87,5 \%)$

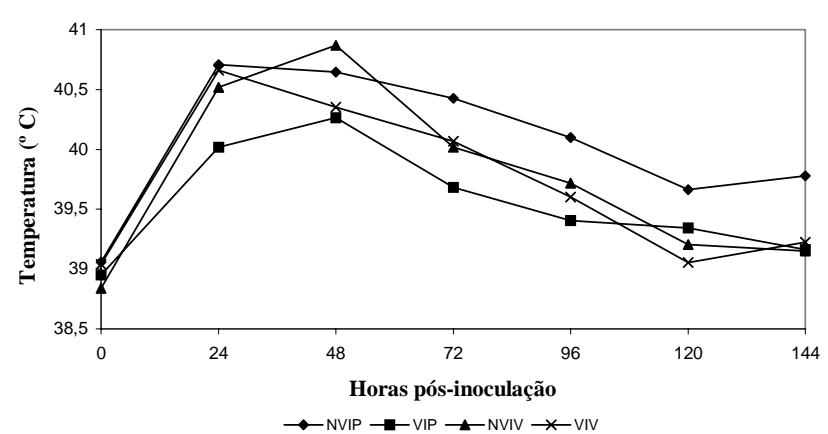

Figura 2. Média da temperatura retal nos grupos de animais do Experimento II.

foi significativamente superior $(\mathrm{P}<0.01)$ quando comparada à proteção $(0 \%)$ dos grupos desafiados pela via intravenosa. Por isso, pode-se sugerir que a via de inoculação usada para o desafio interfere significativamente no efeito da proteção pela vacina. A via intravenosa como método de desafio para teste de vacinas, não reproduz a rota natural de infecção do agente e a inoculação de $10^{9}$ a $10^{10}$ UFC/animal é provavelmente muito alta quando comparada com a infecção natural [13]. A campo, supõe-se que o desafio do agente não seja tão alto, e a inoculação do $S$. suis diretamente na corrente sanguínea do animal facilita a ação da bactéria. $\mathrm{O}$ título de anticorpos presentes no animal pode não ser suficiente para neutralizar a grande quantidade de bactérias utilizadas no desafio e lançadas diretamente na corrente sangüínea. Portanto, mesmo os animais vacinados não conseguiriam boa proteção contra o desafio do agente quando desafiados pela via intravenosa.

No experimento II, nenhum animal apresentou sinais nervosos ou respiratórios. Esse resultado não era esperado, pois foi utilizada a mesma amostra de $S$. suis do experimento I. As causas da ausência dos sinais nervosos não foram bem entendidas. Uma diferença importante que ocorreu entre os dois experi- 
mentos foi a idade de desafio dos animais. No experimento I o desafio foi aos 60 dias de idade e no experimento II aos 88 dias de idade. Reams et al. [8] citam que os suínos são susceptíveis a infecção pelos $S$. suis de 4 as 12 semanas de idade. Em diversos trabalhos pesquisados, os autores utilizaram diversas idades para desafio, variando entre 14 [3] e 63 dias [15], não sendo relatada na literatura consultada idades de desafio superiores. Vários autores utilizaram idade de 50 a 56 dias para desafiar os leitões $[4,5,7,14]$ e os animais desafiados apresentaram sinais nervosos clássicos da doença. No experimento I, onde os animais foram desafiados com 60 dias de idade, 25 animais apresentaram sinais nervosos clássicos, confirmando os dados de literatura. Entretanto, no experimento II, a idade de desafio aos 88 dias, foi superior a idade utilizada por outros pesquisadores. Essa idade elevada de desafio pode ter contribuído para a ausência dos sinais nervosos no experimento II.

Os resultados apresentados no isolamento do agente e as médias das contagens bacterianas foram significativamente menores $(\mathrm{P}<0,05)$ nos grupos vacinados em relação aos grupos não vacinados em ambos os experimentos. Apesar da vacina não ter apresentado redução significativa nos sinais clínicos e lesões nos grupos desafiados pela via intravenosa, parece estimular o sistema imune e ajudar a eliminar o agente do organismo. Wisselink et al. [15] relatam que os animais vacinados possuíam maior chance de eliminar o agente do organismo do que os animais não vacinados, mesmo quando não apresentavam redução significativa nas lesões e sinais clínicos.

$\mathrm{O}$ isolamento do $S$. suis nas meniges de animais do grupo NVIP, NVIV e VIV foi um resultado não esperado, pois não apresentavam sinais clínicos ou lesões compatíveis com meningite. Uma possível explicação para os isolamentos de $S$. suis no cérebro dos animais no experimento II é que o tempo de 144 horas não foi suficiente para causar os quadros de meningite. A bactéria estava presente no cérebro, entretanto não foi capaz de causar danos suficientes para a manifestação dos sinais nervosos ou das lesões, provavelmente, devido aos animais serem mais velhos e consequientemente mais resistentes à doença.

\section{CONCLUSÕES}

Analisando-se os resultados apresentados, podemos a concluir que a via de desafio intravenosa não se mostrou adequada para avaliar da proteção de uma bacterina autógena contra Streptococcus suis e a via intraperitoneal apresentou aspectos favoráveis. Finalmente, a vacina mostrou ser eficaz na prevenção da infecção pelo Streptococcus suis sorotipo 2 de alta virulência, protegendo os animais com uma eficácia estimada de $87,5 \%$, em condições experimentais.

\section{NOTAS INFORMATIVAS}

${ }^{1}$ Microvet, Microbiologia Veterinária Especial, Viçosa-MG Brasil 35430-000.

${ }^{2}$ Difco Laboratories, Detroit, EUA.

${ }^{3}$ Epiinfo 6.4, CDC, Atlanta, EUA.

\section{REFERÊNCIAS}

1 Aarestup F. M., Rasmussen S. R., Artusson K. \& Jensen N. E. 1998. Trends in the resistance to antimicrobial agents of Streptococcus suis isolates from Denmark and Sweden. Veterinary Microbiology. 63 (Suppl 1): 71-80.

2 Andresen L.O. \& Tegmeier C. 2001. Passive immunization of pigs against experimental infection with Streptococcus suis type 2. Veterinary Microbiology. 81 (Suppl 3): 331-334.

3 Amass S., Stevenson G., Knox K. \& Reed A. 1999. Efficacy of an autogenous vaccine preventing streptococcis in piglets. Food Animal Practice. 17: 480-484.

4 Berthelot-Hérault F., Gottschalk M., Labbé A., Cariolet R. \& Kobisch M. 2001. Experimental airborne transmission os Streptococcus suis capsular type 2 in pigs. Veterinary Microbiology. 82 (Suppl 1): 69-80.

5 Blecha F., Reddy D.N., Chitko-Mckow C.G., Mcvey D.S., Chengappa M.M., Goodband R.D. \& Nelssen J.L. 1995. Influence of recombinant bovine interleukin-1 beta and interleukin-2 in pigs vaccinated and challenged with Streptococcus suis. Veterinary Immunology and Immunopathology. 44: 329-346. 
6 Blouin C., Higgins R., Gottschalk M. \& Simard J. 1994. Evaluation of the antibody response in pigs vaccinated against Streptococcus suis capsular type 2 using a double-antibody sandwich enzyme-liked immunosorbent assay. Canadian Journal of Veterinary Research. 58: 49-54.

7 Jacobs A.A.C., Van Den Berg A.J.G., Baars J.C. \& Loeffen P.L.W. 1996. Protection of experimentally infected pigs by suilysin, the tiol-activated haemolysin of Steptococcus suis. Veterinary Record. 139: 225-288.

8 Reams R.Y., Glickmam L.T., Harrinton D.D., Bowersock T.L. \& Thacker H.L. 1993 Streptococcus suis infections in swine: a retrospective study of 256 cases. Part I: Epidemiologic factors and antibiotic susceptibility patterns. Journal of Veterinary Diagnostic Investigation. 6: 326-334.

9 Santos J.L., Del'Arco A.E., Ribeiro M.C.E., \& Guimarães W. 1999. Distribuição de sorotipos de Streptococcus suis em suínos clinicamente doentes no Brasil. In: IX Congresso Brasileiro de Veterinários Especialistas em Suínos (Belo Horizonte, Brasil). pp. 239-240.

10 Simonson R., Carlson M., Freese W. \& Abraham A. 1989. Streptococcus suis immunology: stimulation of immunity using a commercial bacterin (Strep Bac). In: Proceedings of the Annual Meeting of the American Association of Swine Practitioners (Des Moines, U.S.A.). pp. 83-85.

11 Staats J.J., Feder I., Okwumabua O. \& Chengappa M.M. 1997. Streptococcus suis: past and present. Veterinary Research Communication. 21:381-387.

12 Torremorell M. \& Pijoan C. 1996. Intraperitoneal vaccination against Streptococcus suis serotype 2 with an autogenous vaccine. Proceedings of the 14th IPVS Congress (Bologna, Italy). p. 57.

13 Torremorell M., Pijoan C. \& Dee S. 1999. Experimental exposure of young pigs using a pathogenic strain of Streptococcus suis serotype 2 and evaluation of this method for disease prevention. Canadian Journal of Veterinary Research. 63: 269275.

14 Wisselink H.J., Vecht U., Stockhofe-Zurwieden N. \& Smith H.E. 2001. Protection of pigs against challenge whith virulent Streptococcus suis type 2 strains by a muraminidase-released protein and extracellular factor vaccine. Veterinary Record. 148: 473-477.

15 Wisselink H. J., Stockhofe-Zurwieden N., Peperkamp K., Hilgers L.A.T. \& Smith H. E. 2002. Assessment of protection efficacy of live and killed vaccines bases on a non-encapsulated mutant of Streptococcus suis serotype 2. Veterinary Microbiology. 84 (Suppl 2): 155-168. 